\title{
REVIEW
}

\section{Quantifying digital vascular disease in patients with primary Raynaud's phenomenon and systemic sclerosis}

\author{
Ariane L Herrick, Stuart Clark
}

In primary and secondary Raynaud's phenomenon, measurement of activity or severity, or both, of the digital vascular disease is a major challenge. We need to identify objective measures of digital vascular disease that are helpful in predicting those patients with Raynaud's who have underlying connective tissue disease, and to measure reliably digital vascular disease progression, and responses to treatment.

None of the various physiological measurement techniques used in the assessment of patients with primary or secondary Raynaud's are ideal. In this review we outline these techniques, highlighting their applications and limitations. The discussion concentrates on the physiological assessment of patients with primary Raynaud's phenomenon (PRP) and systemic sclerosis (SSc), but is also applicable to other connective tissue diseases. We have not included biochemical markers of vascular injury or measurement of tissue oxygen levels.

\section{The nature of the problem}

In PRP, episodic ischaemia in response to cold exposure or to emotional stimuli is entirely reversible: absence of tissue damage is a defining feature. ${ }^{1}$ In contrast, SSc may be associated with irreversible tissue damage with ulceration, scarring and sometimes gangrene, and structural change occurs in the vasculature. ${ }^{23}$ Indeed, SSc is probably primarily a disease of the vasculature, although it is not clear how this interrelates with collagen and other connective tissue matrix metabolism. ${ }^{45}$

Assessment of digital vascular disease needs to take into account:

(a) Digital vasospasm. This is best assessed by dynamic testing with standard stimuli, such as a standard cold stress.

(b) Structural vascular disease. This may affect basal blood flow in addition to vascular responses to standard stimuli.

In the patient presenting with Raynaud's phenomenon, we must assess both the microvasculature and the digital arteries. Different physiological measurement techniques may be used in combination, especially if investigators wish to examine both digital artery and microvascular flow. ${ }^{6}$
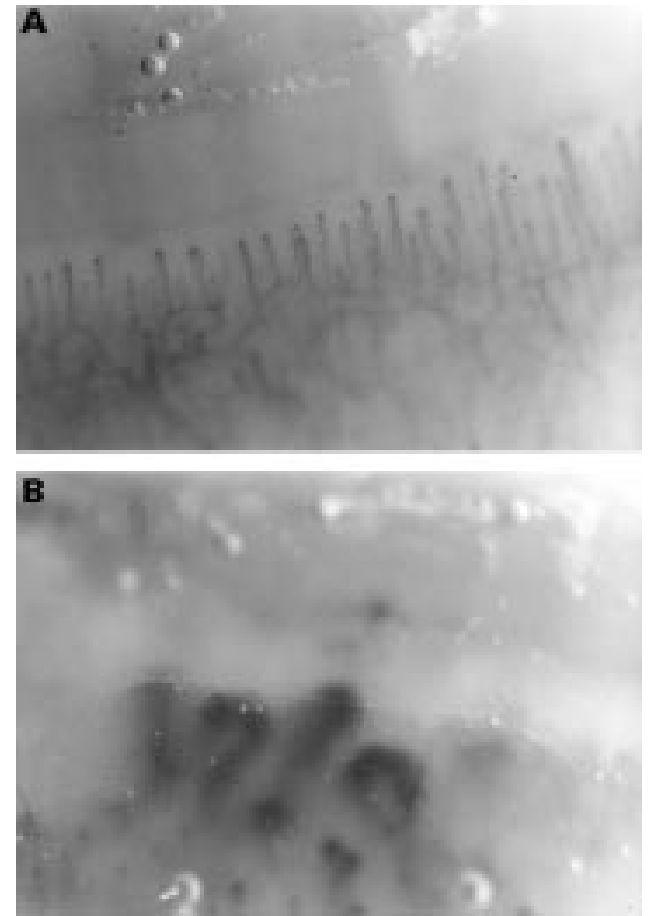

Figure 1 Widefield nailfold capillaroscopy showing $(A)$ normal appearances and (B) dilated loops and loop drop out in a patient with SSc. Magnification in (B) is twice that in $(A)$.

\section{Nailfold microscopy}

On widefield capillaroscopy, characteristic nailfold capillary abnormalities are found in several of the connective tissue diseases, such as capillary dilatation and loop drop out in patients with SSc (fig 1). ${ }^{78}$ Digitised video capillaroscopy has the advantage of allowing measurement of dimensions of individual capillaries (fig 2). ${ }^{9} 10$

Nailfold capillaroscopy is an aid to diagnosis: a patient with Raynaud's phenomenon with abnormal capillaries is likely to have or develop underlying connective tissue disease. Abnormalities on nailfold microscopy in patients with SSc have now been described in several cross sectional studies, and while many of these have been qualitative, some do include quantitative or semi-quantitative assessment. ${ }^{9-18}$ Quantifying nailfold capillary abnormalities is attractive, as it may allow measurement of microvascular disease progression over time.
Accepted for publication 13 November 1997 

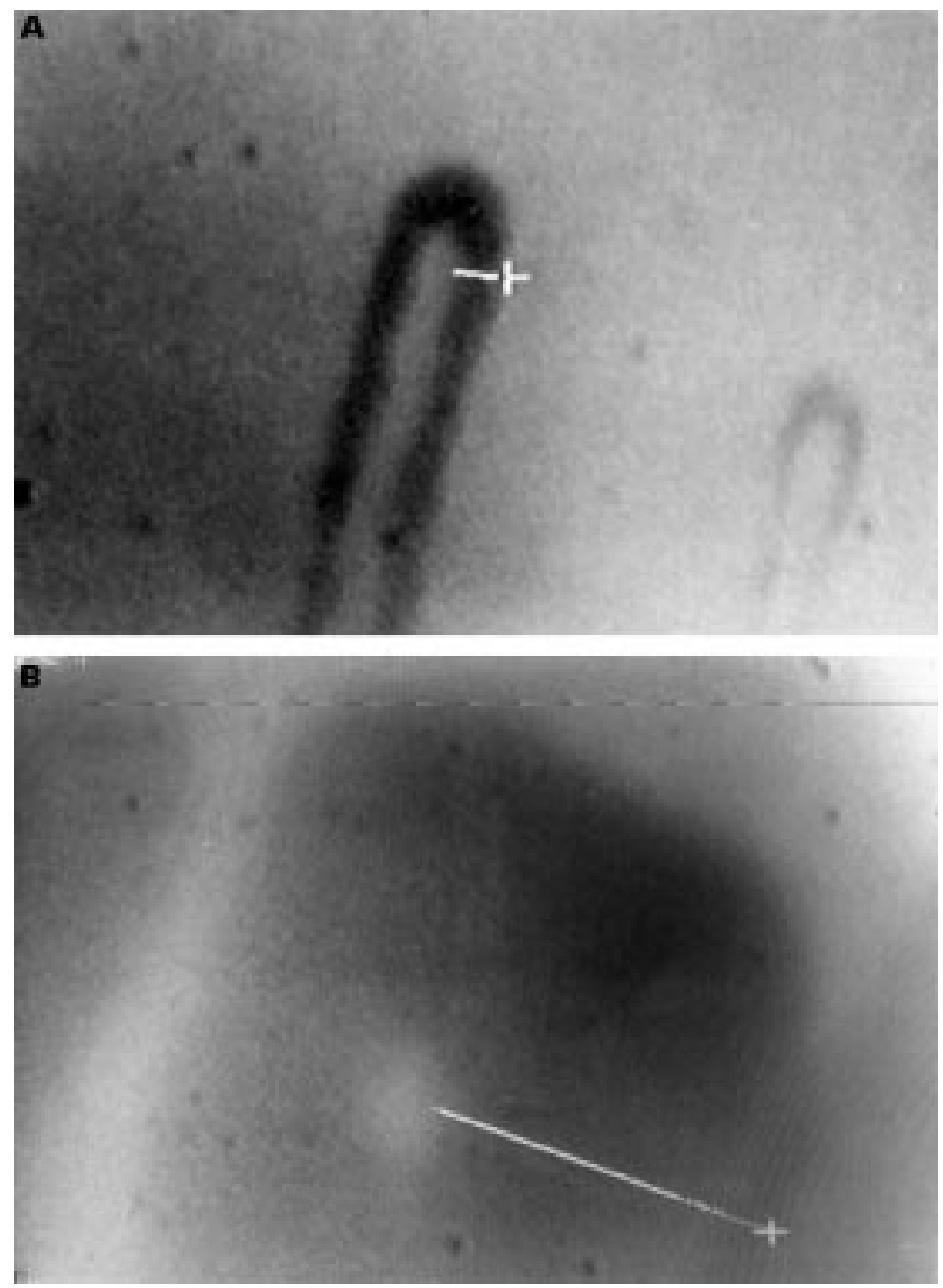

Figure 2 Video capillarosopy showing calculation of the diameter of the venous limb in (A) a healthy control subject and (B) a patient with SSc (original magnification $\times 600$ ).

Quantitative assessment of the nailfold capillary bed is difficult as dimensions vary between capillaries, especially in connective tissue disease, and capillaries can be irregular in shape and criss-cross. ${ }^{12}$ We need to develop sensitive and reproducible methods, most probably using image analysis systems, to quantify the capillary abnormalities and test these in longitudinal studies.

Recently we and others reported that patients with PRP have minor changes on capillaroscopy compared with control subjects, ${ }^{915}$ suggesting that patients with PRP may have structural microvascular changes, albeit to a lesser degree than those with SSc. This challenges the widely held view that patients with PRP experience vasospasm in the absence of structural vascular change, and shows how nailfold microscopy may throw new light into the pathogenesis of Raynaud's phenomenon.

Two related techniques require special mention. Firstly, fluorescence videomicroscopy can be used to measure capillary permeability, which is increased in SSc. ${ }^{19}$ This technique could be used to evaluate drug induced changes in capillary permeability. ${ }^{20}$ Secondly, when nailfold capillaries are examined under a microscope connected to a video analysis system, individual red blood cells can be seen and their velocities measured. ${ }^{8}$ When the nailbed is cooled, red blood cell velocity will reduce, and the "flow stop" time may differentiate between patients with PRP, SSc, and healthy controls. ${ }^{21}$ Capillary red blood cell velocities, before and after a cold challenge, have been used to monitor responses to vasoactive therapy ${ }^{82}$ and normalisation may predict clinical responses to vasodilator therapy. ${ }^{23}$

\section{CONCLUSIONS}

Nailfold capillaroscopy has enormous potential in the assessment of digital vascular disease. Widefield microscopy is inexpensive, easy to use, and useful prognostically in patients presenting with Raynaud's phenomenon. Direct visualisation of capillaries of different patient subgroups may raise fundamental questions regarding pathogenesis. Video capillaroscopy may allow quantitation of microvascular disease progression over time and therefore be an important research tool. While current techniques of quantifying capillary abnormalities are not ideal, in that they are time-consuming or incorporate a degree of subjectivity, or both, this is an area being actively researched. Techniques used to monitor change within a person may include dynamic testing, monitoring changes in red blood cell velocity.

\section{Laser Doppler blood flow monitoring}

Laser Doppler flowmetry is well established in the measurement of cutaneous microcirculatory flow. ${ }^{24}$ The depth of penetration of skin by the laser beam varies depending on the exact equipment used. It is usually about $1 \mathrm{~mm}$, including all elements of the dermis, from superficial nutritional capillaries to deeper thermoregulatory vessels. The technique depends on the Doppler broadening of laser light scattered by moving particles. The broadened signal, when detected and analysed, gives information about moving particle density and flux (the product of density and velocity). From this an average velocity can also be obtained: flux divided by density. Flux is the parameter used to express blood flow. The different scattering and absorption properties of different wavelengths of light allows different depths of tissue to be monitored. For example, nutritional blood flow can be separated from thermoregulatory flow ${ }^{25}$ using the more highly absorbing properties of green light in perfused tissue.

Laser Doppler monitoring is non-invasive (fig 3) and single channel equipment relatively inexpensive. However, an important problem is the large site to site signal variation. Even a minute change in position or orientation of the probe can cause significant changes in estimation of blood flow. This means that two signals from different sites (or signals from what is believed to be the same site at different points in time) cannot be directly compared, so minimising the usefulness of the technique for monitoring change within a person over time. 


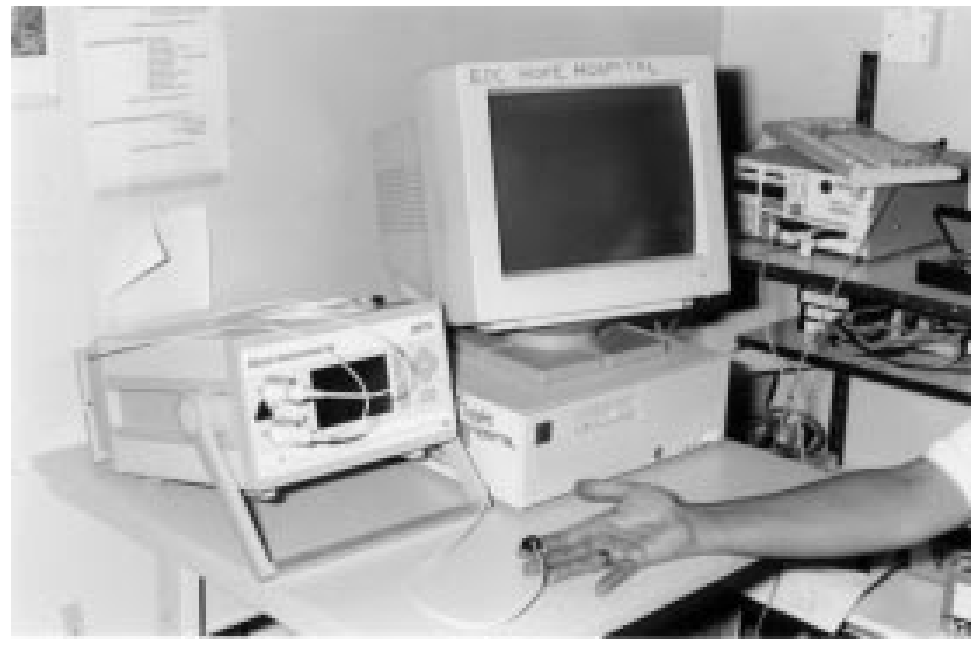

Figure 3 Commercially available laser Doppler blood flow monitoring system (the probe is attached to the right index finger-single channel equipment).

To some extent this difficulty can be overcome by incorporating dynamic testing into the microcirculatory assessment. This means that the probe remains in a fixed position, a standard stimulus is applied, and the change in blood flow is measured. Different methods of dynamic testing include:

(a) Local warming or cooling of the fingers, dorsum of hand or foot, using a variety of techniques and protocols. ${ }^{26-29}$

(b) Whole body warming or cooling. ${ }^{30} 31$ This permits examination of central thermoregulatory responses.

(c) Post-occlusive reactive hyperaemia. ${ }^{32-34}$

Many studies have been cross sectional, comparing patient groups and controls: others have assessed treatment responses, looking for improved blood flow after vasodilator and other therapies. Results need to be interpreted with caution, because the ability to detect differences in blood flow responses between groups will depend not only upon the subjects and the sensitivity and reproducibility of the laser Doppler equipment but also upon the stimulus applied, and the area of skin being studied. To take one example, Toms and Cooke found that heating the sclerodermatous hand from $24^{\circ} \mathrm{C}$ to $40^{\circ} \mathrm{C}$ caused an increase in laser Doppler flux measured at the finger pulp. This did not occur in the control subjects, who were probably maximally vasodilated at $24^{\circ} \mathrm{C} .^{35}$ However, Geirsson et al reported that patients with SSc responded in the same way as controls to "local heating". ${ }^{36}$ The stimulus applied in this study (heating a small area of skin) was very different from the warm water immersion of Toms and Cooke, and different skin sites were examined. Therefore it is very difficult to compare such studies. This difficulty in comparing studies is worth emphasising, and applies to some extent to all methods of digital vascular assessment. Also, comparisons of "baseline" laser Doppler flux in patients with SSc and controls are very dependent upon the area of skin tested: at ambient temperatures flux tends to be increased in the skin of the dorsum of the hand in patients with SSc com- pared with controls, ${ }^{28}{ }^{37}$ but reduced in the fingers. ${ }^{26}$

The difficulties in interpreting many studies are compounded by small patient numbers and sometimes poorly defined patient groups. Bartelink et al reported changes in laser Doppler flux in response to a finger cooling test in a large study of PRP, secondary Raynaud's, and healthy controls. Patients with primary and secondary Raynaud's had reduced flux, but there was substantial overlap between groups, and patients with primary Raynaud's could not be distinguished from those with secondary Raynaud's on the basis of their test. ${ }^{38}$ Skin temperatures and Doppler fluxes were consistently lower in women than men, emphasising the importance of sex matching/correction in studies of Raynaud's. These authors assessed the reproducibility of their technique, ${ }^{39}$ and are to be congratulated as few studies have included assessments of reproducibility. Disappointingly (but perhaps predictably) reproducibility for the laser Doppler flow measurements was poor, and the authors concluded that the test has little value in the monitoring of individual cases, but might reasonably be used to look for differences between large patient groups. This suggests that studies that have used laser Doppler techniques in the evaluation of response to treatment should be interpreted with caution. $^{4041}$

Another method of "dynamic" testing using laser Doppler is to assess blood flow responses during and after iontophoresis of charged vasoactive substances through the skin. ${ }^{42} 43$ This methodology allows examination of endothelial dependent and endothelial independent responses by comparing effects of the endothelial dependent acetylcholine chloride with the endothelial independent sodium nitroprusside. In the future this technique may permit assessment of disease progression and responses to treatment. However, even with very specific dynamic stimuli the reproducibility of the technique is not ideal. ${ }^{42}$

New developments of the laser Doppler technique will probably obviate some of the problems such as site to site variability. The new technique of laser Doppler imaging, using scanning laser Doppler equipment, permits measurement of flux over an area rather than a single point, and has the added advantage of not requiring direct contact between a probe and the skin (which might itself influence blood flow). Figure 4 shows an example of the type of image generated by a laser Doppler scanner. So far experience of this scanning laser Doppler technique in patients with Raynaud's phenomenon is very limited ${ }^{37} 44$ and further evaluation is warranted. At present, very few clinical departments have access to laser Doppler imaging equipment.

"Optical Doppler tomography" 45 allows two dimensional cross sections of the microvasculature to be derived, with flow velocity in individual microvessels superimposed on these. Existing laser Doppler techniques allow only an average blood flow reading from a volume to be measured, with no indication of the contribution from the different subsets of 
vessels. This technique is still in its infancy but holds promise.

Laser Doppler flowmetry may be also used to detect return of blood flow after digital artery occlusion. Many studies involving measures of digital systolic pressure therefore incorporate the laser Doppler technique.

CONCLUSIONS

Single probe laser Doppler blood flow monitoring is very sensitive to changes in perfusion but suffers from site to site variability and measurements are often poorly reproducible, even when protocols incorporate dynamic testing. The full potential of laser Doppler remains to be exploited. Newer applications of laser Doppler, including scanning laser Doppler, may prove useful. At present, laser Doppler remains primarily a research tool.

\section{Thermography}

While many studies of patients with Raynaud's phenomenon include measurement of skin temperature at a single point, here we confine ourselves to infrared thermography, which gives a pictorial representation of surface temperature (fig 5). Measurement of skin temperature is an indirect method of blood flow assessment. It is non-invasive, but requires expensive equipment, which should be housed in a temperature and humidity controlled laboratory and so its use has been restricted to specialist centres. ${ }^{46}$

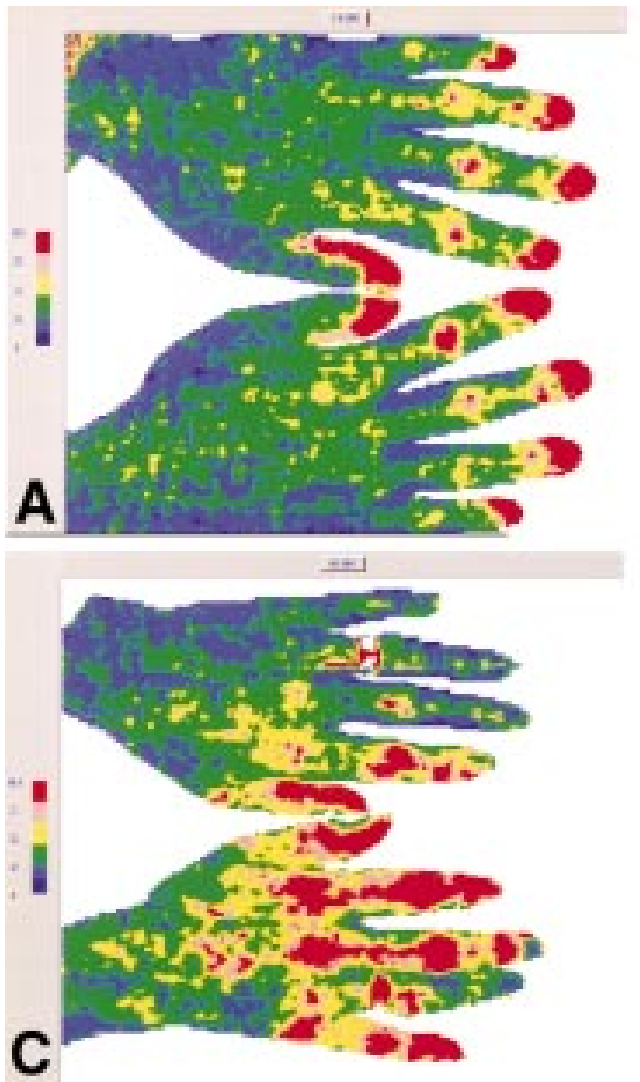

Thermography protocols usually incorporate some form of dynamic testing, and most of the experience in patients with PRP and SSc has included responses to a standard cold challenge. The ability of a patient to rewarm will depend upon the degree to which vasospasm induced by the cold challenge can be reversed within the duration of the test. The pattern of rewarming will also be affected by underlying structural vascular disease. Clearly the precise conditions of the test, for example the duration of the rewarming period and the ambient room temperature, will influence results.

At least three studies have reported how analysis of rewarming curves differentiates between healthy controls and patients with PRP or SSc (fig 6). ${ }^{47-49}$ Parameters that are quantified include the time interval from the end of the cold challenge to the onset of rewarming, the rate of rewarming and the maximum temperature recovery, ${ }^{49}$ the degree of temperature variation between different areas of the hands, ${ }^{48}$ and an index combining the temperature gradient along the index finger during rewarming with the temperature change of the finger after cold challenge. ${ }^{47}$ There are concerns about the reproducibility of the rewarming curve. ${ }^{50}$

Thermography has been used to quantify responses to drug treatment. Some studies incorporated dynamic responses ${ }^{47}{ }^{51-56}$ whereas others simply used a "resting" hand temperature, or index of hand temperature, measured

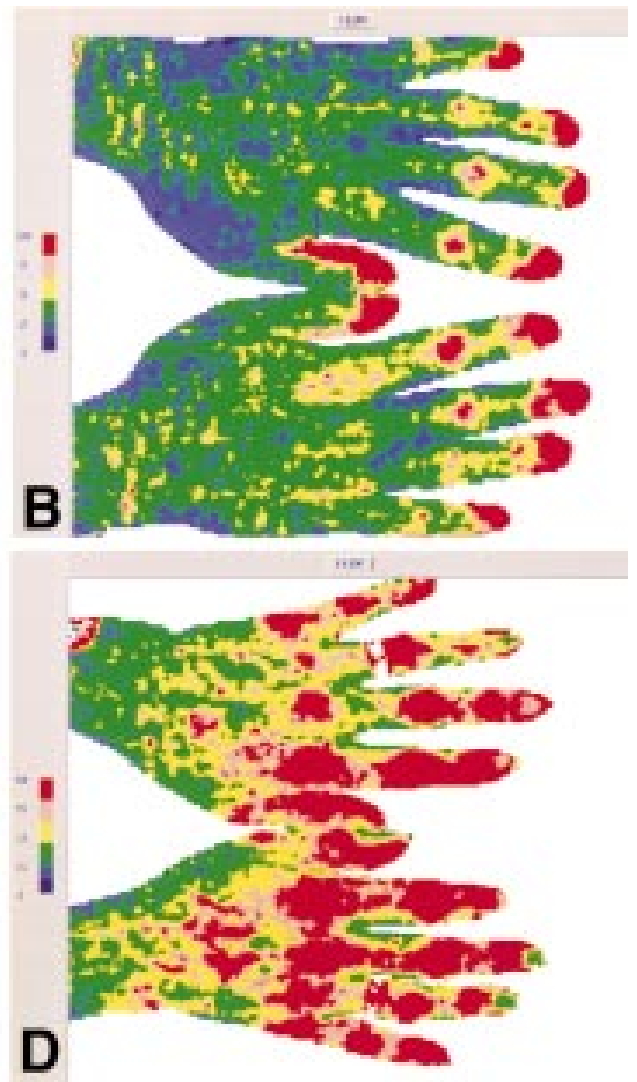
pronounced changes with temperature. All images were acquired using a Moor Instruments MoorLDI imager. The artefacts on both ring fingers of the SSc patients are because of reflections from rings on those fingers. 


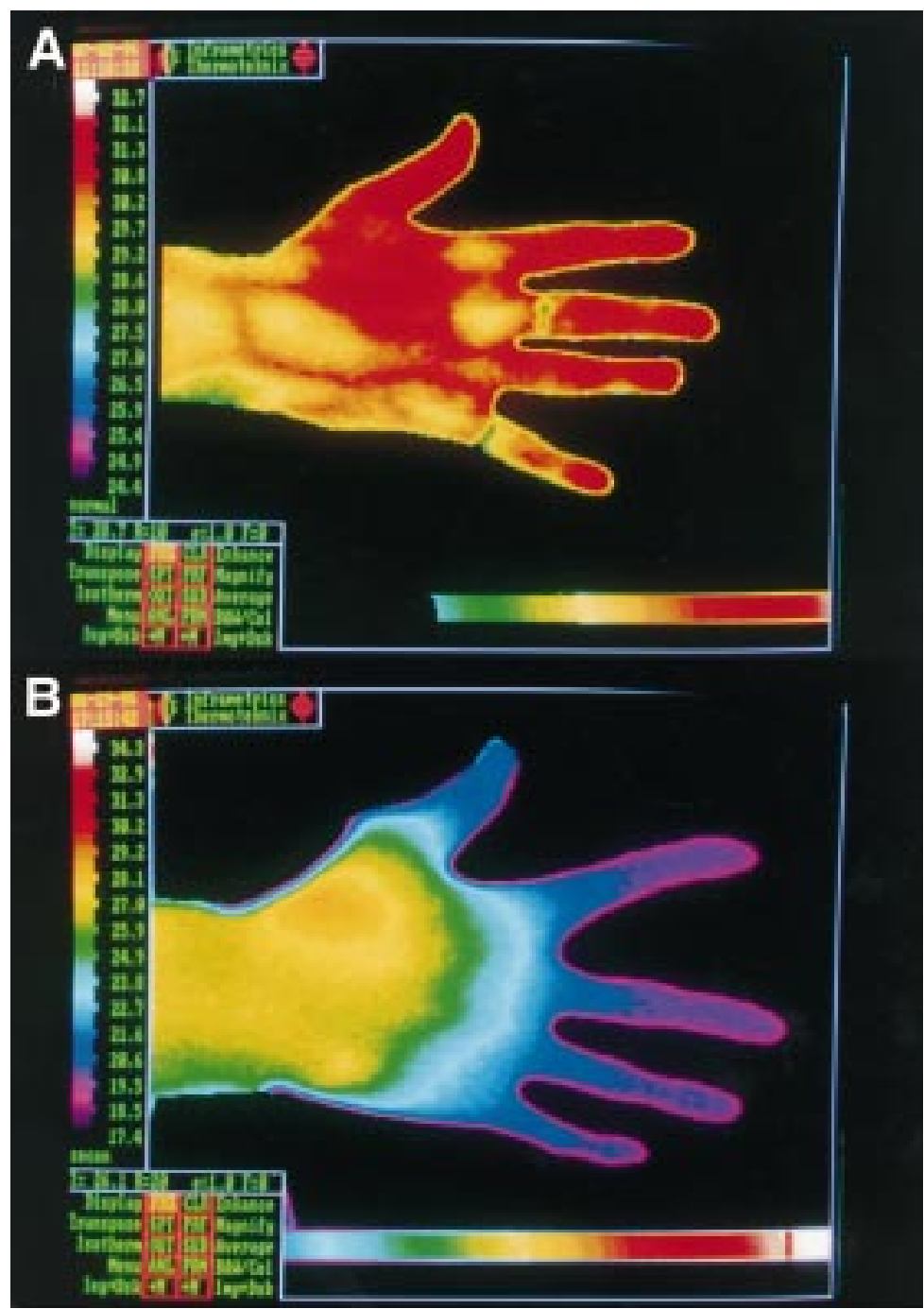

Figure 5 Thermographic image under standard baseline conditions of the dorsum of the hand of $(A)$ a healthy control and (B) a patient with SSc, showing reduced temperatures of the fingers compared with the dorsum of the hand. Images were acquired using an Inframetrics $600 \mathrm{~m}$ thermography camera.

before and after treatment. ${ }^{5758}$ However, because of concerns about reproducibility, reservations should apply when interpreting results.

\section{CONCLUSIONS}

Thermography measures blood flow indirectly, by measuring skin surface temperature. Most studies of primary and secondary Raynaud's incorporate dynamic testing in response to a standard cold challenge. The patterns of rewarming differ between control, primary and secondary Raynaud's, but the use of thermography for monitoring disease progression/ response to treatment is less well established, especially as studies examining the reproducibility of the technique are lacking.

\section{Finger systolic blood pressure measurements}

The responses of digital artery systolic pressures to temperature change has long been advocated as a useful test to identify patients with Raynaud's phenomenon..$^{59}$ Measurement of finger systolic pressure responses is a test of
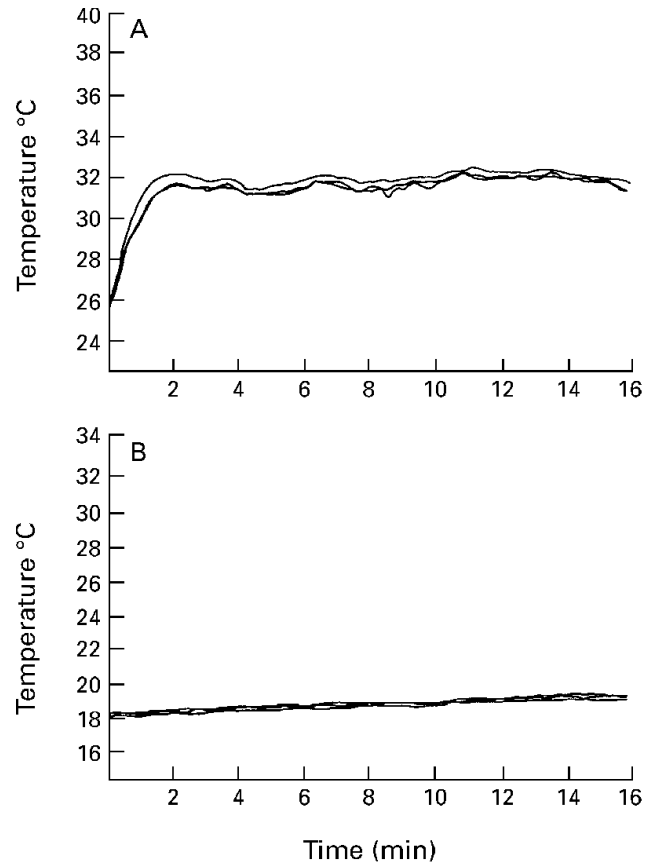

Figure 6 Rewarming curves (from index, middle, and ring fingers) from (A) a healthy control subject and (B) a patient with SSC, showing almost no rewarming.

the digital arteries, in contrast with nailfold microscopy and laser Doppler blood flow monitoring, which assess the microcirculation. Therefore these different methodologies may complement each other in an assessment of digital vascular disease.

A digital blood pressure cuff is placed around the proximal phalanx, the cuff inflated to suprasystolic pressure, and then the opening pressure at which the pulse reappears during deflation is recorded. The temperature of the finger can be raised or lowered by varying the temperature of water circulating in a second cuff placed around the middle phalanx. ${ }^{60} \mathrm{~A}$ photoelectric transducer, ${ }^{60}$ strain gauge plethysmography, ${ }^{6162}$ or laser Doppler flowmetry ${ }^{63}$ can be used to identify the opening pressure. Gauging the "appearance" of the pulse inevitably adds a degree of subjectivity to the technique. Some investigators have combined local cooling of the finger with whole body cooling, ${ }^{6465}$ the rationale being that whole body cooling will help to standardise the test, by eliminating some of the interindividual variation in sympathetic nervous system stimulation at the time of the test.

Patients with Raynaud's phenomenon demonstrate a more pronounced decrease of systolic pressures in response to cooling than control subjects, in both the fingers and the toes. ${ }^{66}$ Allen et al developed an index for vasospasm based on the severity of the stimuli required to produce complete vasospasm, and found that this correlated with the symptomatic grading of vasospasm. ${ }^{63}$ Several factors contribute to increased responsiveness to a cold challenge, including excessive vasoconstriction and digital arterial obstruction. ${ }^{64}$

Not all authors agree as to whether patients with Raynaud's phenomenon can be differentiated from controls on the basis of digital 
systolic pressure responses. ${ }^{36}{ }^{62-65} 67{ }^{68}$ Methodological and patient population differences between studies may be relevant. In a large and detailed study including controls, "cold sensitive" subjects, patients with PRP, and patients with SSc spectrum disorders, Maricq et al have shown that digital blood pressure responses to temperature change have high sensitivity and specificity in distinguishing between patients with SSc spectrum disorders and PRP, and between patients with PRP and cold sensitive individuals. ${ }^{60}$

A number of studies have used digital systolic pressure responses to assess responses to vasodilator therapy. ${ }^{4169}{ }^{70}$ However, when Wigley et al examined the reproducibility of digital systolic pressure responses they found that patients adapted to the cold challenge: lower temperatures were required to induce a "Raynaud's attack" at the third than at the first examination. ${ }^{61}$ Results must always be interpreted in the light of the reproducibility of the technique.

CONCLUSIONS

Measuring digital systolic pressure responses under standard conditions may help to differentiate between patients with PRP and SSc and control subjects. Therefore ideally a protocol such as that used by Maricq et al ${ }^{60}$ should be incorporated into studies of patients with primary and secondary Raynaud's phenomenon. Restoration of flow after occlusion can be measured using a variety of techniques. While the equipment required may be relatively inexpensive, great care is required if the method is to be clinically useful, and the reproducibility of the method should be established. Further studies are required to assess whether digital systolic pressure responses are useful in monitoring responses to treatment, or quantifying disease progression over time.

\section{Doppler ultrasound}

Doppler ultrasound to detect restoration of arterial pulsation during suprasystolic cuff deflation is well established in the assessment of arteriosclerotic peripheral vascular disease. Another of its uses is its ability to detect digital pulses, and therefore digital artery patency. A scoring system for the hand, based on the number of digital pulses present, has been used in the assessment of vasodilator treatment or other therapeutic intervention, with an increase in the number of identifiable pulses reflecting improvement in the digital circulation..$^{58}{ }^{71-73}$ However, this technique does entail some subjectivity on the part of the observer identifying when a pulse appears.

High resolution ultrasound scanners allow visualisation and measurement of digital arteries. Protocols investigating patients with Raynaud's phenomenon have entailed dynamic testing. Singh et $a l^{4}$ found that the patients with Raynaud's phenomenon could be distinguished from controls on the basis of the degree of change in the calibre of the digital artery on cold exposure. No details were given, however, as to whether the 12 patients studied had primary or secondary Raynaud's, and the reproducibility of the technique was assessed in only two subjects. ${ }^{74}$ Naidu et al also reported that the degree of reduction in digital artery diameter after a standard cold challenge could differentiate between patients with Raynaud's phenomenon and controls, although the technique did not discriminate between PRP and secondary Raynaud's. ${ }^{75}$ Digital artery diameter responses to infusion of different vasoactive agents, for example endothelial dependent and endothelial independent vasodilators, may be useful in helping to elucidate the pathophysiology of Raynaud's. ${ }^{76}$

Using Doppler ultrasound it is also possible to measure blood flow velocity, and responses to cold stress, in different arteries in the hand. This technique may differentiate between Raynaud's and control subjects: between $35^{\circ} \mathrm{C}$ and $25^{\circ} \mathrm{C}$ the vasoconstrictive response was greater in Raynaud's, although patient numbers were small. ${ }^{77}$ These techniques have been used to monitor response to drug treatment. ${ }^{72}$

\section{CONCLUSIONS}

Measurement of digital artery diameter and of arterial blood velocity with high resolution ultrasound, especially in conjunction with dynamic testing, offers a promising technique of quantifying structural digital artery disease, and vasospasm. These techniques could be used to monitor vascular disease progression, but this needs to be clarified in prospective studies. Sophisticated equipment is necessary, however, and the technique remains very much a research tool.

\section{Plethysmography}

Various techniques of plethysmography have been used to assess Raynaud's phenomenon, but none have gained universal acceptance. Most types of plethysmography rely on volume change. In digital venous occlusion strain gauge plethysmography, a blood pressure cuff is placed around the proximal phalanx of the finger and inflated above venous pressure but below arterial pressure. When the cuff is inflated, the volume of the finger will increase because venous return is blocked, and the rate of this swelling immediately after occlusion (as measured by some form of strain gauge) reflects the blood flow into the finger. In Raynaud's phenomenon, this technique has been used to assess differences in blood flow between different subgroups, ${ }^{60}$ responses to temperature change, ${ }^{78}$ the menstrual cycle, ${ }^{79}$ and vasodilator treatment. ${ }^{80}$ Maricq et al found that although mean blood flow measured by venous occlusion plethysmography differed between patients with PRP, SSc spectrum disorders, "cold sensitive" subjects, and controls, the results were not statistically significant. ${ }^{60}$ The technique can be difficult in patients with finger deformities. ${ }^{60}$

Plethysmography (without occlusion) can be also used to detect presence or absence of arterial blood flow. If a strain gauge is placed around the distal phalanx, then pulsatile changes in volume mean that the vessel is patent. This means that strain gauge plethysmography can be used to detect digital systolic 
opening pressure. Engelhart et al suggested that this technique was less sensitive at detecting the low flow rates in patients with SSc after digital occlusion than laser Doppler flowmetry. ${ }^{81}$

The change in amplitude of the plethysmographic signal in response to temperature change, recorded from a strain gauge encircling the distal end of the finger, may be useful in the assessment of severity of Raynaud's phenomenon. ${ }^{82}$ The percentage drop in pulsatility with temperature change is increased in Raynaud's phenomenon, and has been used to quantify vessel constriction. ${ }^{83}$

Microcirculatory volume can be assessed using the technique of infrared photoplethysmography (sometimes termed photoelectrical plethysmography). ${ }^{84} 85$ An infrared light source is directed into the skin of the finger pulp and the amplitude of the tracing recorded from the photoplethysmograph corresponds to the volume of circulating erythrocytes. This technique can be used as the "distal sensor" in studies of digital systolic pressure and to quantify blood flow before and after vasodilator treatment. ${ }^{86}$

CONCLUSION

A small number of studies continue to use permutations of plethysmography to quantify blood flow in studies of patients with Raynaud's phenomenon, usually incorporating some form of dynamic testing. However, equipment needs careful calibration and great care needs to be taken to ensure that recordings are accurate. Reproducibility data are infrequently quoted.

\section{Final conclusion}

There are several physiological measurement techniques for quantifying peripheral vascular disease in patients who have connective tissue disease or in whom connective disease is suspected. Most entail dynamic testing. Many require further validation, however, to assess their sensitivity and specificity in distinguishing between patients with and without underlying structural vascular disease and to assess their ability to quantify disease progression over time. When undertaking these further studies, investigators should ensure adequate patient numbers are included: while it is often difficult to predict these, a "best guess" estimate should be made on the basis of pilot studies.

An important point to remember when discussing different methods of assessing the digital circulation is that with any form of investigation of blood flow, factors contributing to poor reproducibility include not only the exact protocol and equipment used but also the patient's degree of sympathetic tone at the time of the test and, in women, the stage of the menstrual cycle. Variations of blood flow with the menstrual cycle are well recognised. ${ }^{87}$ Also, blood flow varies with age and with whether the patient is male or female. ${ }^{88}$ Another factor is that a very large number of permutations of dynamic testing are possible by varying the "standard conditions" of the test (for example, room temperature, duration of acclimatisation) and by varying the severity and the duration of the dynamic challenge. Thus it is always important to check the exact details of the methodology when interpreting the existing medical literature.

Nailfold capillaroscopy and laser Doppler flow studies assess the microcirculation while digital systolic pressure responses and Doppler ultrasound assess the digital arteries: thermography and plethysmography may reflect both. Therefore different techniques complement one another: ideally centres with an interest in digital blood flow should have access to measurements of both microvascular and digital artery flow.

While nailfold microscopy and detection of peripheral pulses by Doppler ultrasound are used in many centres as part of the clinical assessment of patients with connective tissue disease, the other techniques are essentially research tools. Refining existing techniques, and developing new methods of quantifying digital vascular disease must be a priority for clinicians and scientists interested in primary and secondary Raynaud's phenomenon. This will help us to evaluate new vasoactive agents as potential treatments for our patients.

We are grateful to Professor Malcolm Jayson and Dr Rodney Gush for helpful discussions.

1 Allen EV, Brown GE. Raynaud's disease: a critical review of minimal requisites for diagnosis. Am J Med Sci minimal requisites

2 Campbell PM, LeRoy EC. Pathogenesis of systemic sclerosis: a vascular hypothesis. Semin Arthritis Rheum 1975;4:351-68.

3 Prescott RJ, Freemont AJ, Jones CJP, Hoyland J, Fielding P. Sequential dermal microvascular and perivascular changes in the development of scleroderma. J Pathol 1992;166: $255-63$

4 Jayson MIV. Systemic sclerosis: a collagen or microvascular disease? BMJ 1984;288:1855-7.

5 LeRoy EC. A brief overview of the pathogenesis of scleroderma (systemic sclerosis). Ann Rheum Dis 1992;51: $286-8$.

6 Engelhart M, Seibold JR. The effect of local temperature versus sympathetic tone on digital perfusion in Raynaud's phenomenon. Angiology 1990;41:715-23.

7 Maricq HR, LeRoy EC. Patterns of finger capillary abnormalities in connective tissue disease by "wide-field" abnormalities in connective tissue disease by
microscopy. Arthritis Rheum 1973;16:619-28.

8 Bollinger A, Fagrell B. Clinical capillaroscopy. Toronto: Bollinger A, Fagrell B. Chin

Hogrefe and Huber, 1990 .
Bukhari M, Herrick AL, Moore T, Manning J, Jayson MIV. Bukhari M, Herrick AL, Moore T, Manning J, Jayson MIV.
Increased nailfold capillary dimensions in primary Raynaud's phenomenon and systemic sclerosis. Br J Rheumatol 1996;35:1127-31.

10 Kabasakal Y, Elvins DM, Ring EFJ, NcHugh NJ. Quantitative nailfold microscopy findings in a population with connective tissue disease and in normal healthy controls. Ann Rheum Dis 1996;55:507-12.

11 Lee P, Leung FY, Alderdice C, Armstrong SK. Nailfold capillary microscopy in the connective tissue diseases: a semiquantitative assessment. J Rheumatol 1983;10:930-8.

12 Lefford F, Edwards JCW. Nailfold capillary microscopy in connective tissue disease: a quantitative morphological
analysis. Ann Rheum Dis 1986;45:741-9.

13 Maricq HR. Comparison of quantitative and semiquantitative estimates of nailfold capillary abnormalities in scleroderma spectrum disorders. Microvasc Res 1986;32: 271-6.

14 Houtman PM, Kallenberg CGM, Fidler V, Wouda AA. Diagnostic significance of nailfold capillary patterns in patients with Raynaud's phenomenon. J Rheumatol 1986;13:556-63.

15 Statham BN, Rowell NR. Quantification of the nail fold capillary abnormalities in systemic sclerosis and Raynaud's syndrome. Acta Derm Venereol (Stockh) 1986;66:139-43.

16 Carpentier PH, Maricq HR. Microvasculature in systemic sclerosis. Rheum Dis Clin North Am 1990;16:75-91.

17 ter Borg EJ, Piersma-Wichers G, Smit AJ, Kallenberg CGM, Wouda AA. Serial nailfold capillary microscopy in primary Raynaud's phenomenon and scleroderma. Semin Arthritis Rheum 1994;24:40-7.

18 Michoud E, Poensin D, Carpentier PH. Digitized nailfold capillaroscopy. Vasa 1994;23:35-42.

19 Bollinger A, Jager K, Siegenthaler W. Microangiopathy of progressive systemic sclerosis. Evaluation by dynamic fluoprogressive systemic sclerosis. Evaluation by dynamic fluo-
rescence videomicroscopy. Arch Intern Med 1986;146: rescence $1541-5$. 
20 Grassi W, Core P, Carlino G, Cervini C. Acute effects of single dose nifedipine on cold-induced changes of microvascular dynamics

21 Mahler F, Saner H, Boss C, Annaheim M. Local cold exposure test for capillaroscopic examination of patients with Raynaud's syndrome. Microvasc Res 1987;33:422-7.

22 Jacobs MJMM, Lemmens HAJ. Microcirculatory changes in patients with primary Raynaud's phenomenon after
treatment with buflomedil. Int J Microcirc Clin Exp 1985; 4:63-8.

23 Hahn M, Klyscz T, Junger M, Rassner G. Local cold exposure test as therapy control in patients with Raynaud's phenomenon: comparison between laser Doppler fluxmetry and simultaneous red blood cell velocity measurements in nailfold capillaries. Br J Dermatol 1995; 133:704-9.

24 Schabauer AMA, Rooke TW. Cutaneous laser Doppler flowmetry: applications and findings. Mayo Clin Proc 19wmetry: applicat

25 Gush RJ, King TA. Discrimination of capillary and arteriovenular blood flow in skin by laser Doppler flowmetry. Med Biol Eng Comput 1991;29:387-92.

26 Goodfield MJD, Hume A, Rowell NR. The effect of simple rewarming procedures on finger blood flow in systemic sclerosis. Br J Dermatol 1988;118:661-8.

27 Graafsma SJ, Wollersheim H, Droste HT, ten Dam MAGJ van Tits $\mathrm{LJH}$, Reyenga J, et al. Adrenoceptors on blood cells from patients with primary Raynaud's phenomenon. Clin Sci 1991;80:325-31.

28 Valentini G, Leonardo G, Moles DA, Apaia MR, Maselli R, Tirri G, et al. Transcutaneous oxygen pressure in systemic sclerosis: evaluation at different sensor temperatures and relationship to skin perfusion. Arch Dermatol Res 1991; 283:285-8.

29 Walmsley D, Goodfield MJD. Evidence for an abnormal peripherally mediated vascular response to temperature in peripherally mediated vascular response to temperature in
Raynaud's phenomenon. Br J Rheumatol 1990;29:181-4.

30 Engelhart M, Kristensen JK. Raynaud's phenomenon: blood supply to fingers during indirect cooling, evaluated by laser Doppler flowmetry. Clin Physiol 1986;6:481-8.

31 Lau CS, Khan F, Brown R, McCallum P, Belch JJF. Digita blood flow responses to body warming, cooling, and rewarming in patients with Raynaud's phenomenon. Angiology 1995;46:1-10.

32 Goodfield M, Hume A, Rowell N. Reactive hyperemic responses in systemic sclerosis patients and healthy controls. J Invest Dermatol 1989;93:368-71

33 Wollersheim H, Reyenga J, Thein T. Postocclusive reactive hyperemia of fingertips, monitored by laser Doppler velocimetry in the diagnosis of Raynaud's phenomenon. Microvasc Res 1989;89:286-95.

34 Wigley FM, Wise RA, Mikdashi J, Schaefer S, Spence RJ. The post-occlusive hyperemic response in patients with
systemic sclerosis. Arthritis Rheum 1990;33:1620-5.

35 Toms SL, Cooke ED. A comparison of the functioning of arterivenous anastomoses in secondary Raynaud's phenomenon and control subjects in response to local hand warming. Int Angiol 1995;14:74-9.

36 Geirsson AJ, Jonsson GS, Asgeirsdottir LP. Functional study of the dermal microcirculation in systemic sclerosis. Scand J Rheumatol 1994;23:73-6.

37 Aghassi D, Monoson T, Braverman I. Reproducible measurements to quantify cutaneous involvement in scleroderma. Arch Dermatol 1995;131:1160-6.

38 Bartelink ML, Wollersheim H, Leesmans E, de Boo $T$, Thein T. A standardised finger cooling test for Raynaud's phenomenon: diagnostic value and sex differences. Eur phenomenon: diagnostic

39 Bartelink ML, Wollersheim H, Jansen RWM, Theeuwes A, Thein T. Reproducibility of the finger cooling test. Microvasc Res 1993;45:65-73.

40 Bunker CB, Reavley C, O'Shaughnessy DJ, Dowd PM. Calcitonin gene-related peptide in treatment of severe peripheral vascular insufficiency in Raynaud's phenomenon. Lancet 1993;342:80-2.

41 Whitmore SE, Wigley FM, Wise RA. Acute effect of topical minoxidil on digital blood flow in patients with Raynaud's phenomenon. J Rheumatol 1995;22:50-4.

42 Anderson ME, Hollis S, Moore T, Jayson MIV, Herrick AL. Non-invasive assessment of vascular reactivity in forearm skin of patients with primary Raynaud's phenomenon and systemic sclerosis. Br J Rheumatol 1996;35:1281-8.

43 Khan F, Litchfield SJ, McLaren M, Veale DJ, Littleford RC, Belch JJF. Oral L-arginine supplementation and cutaneous vascular responses in patients with primary Raynaud's phevascular responses in patients with primary

44 Seifalian AM, Stansby G, Jackson A, Howell K, Hamilton G. Comparison of laser Doppler perfusion imaging, laser Doppler flowmetry, and thermographic imaging for assessment of blood flow in human skin. Eur J Vasc Surg 1994;8:65-9.

45 Chen Z, Milner TE, Dave D, Nelson JS. Optical Dopple tomographic imaging of fluid flow velocity in highly scattering media. Optics Letters 1997;22:64-6.

46 Feldman F. Thermography of the hand and wrist: practical applications. Hand Clin 1991;7:99-112.

47 Kyle V, Parr G, Salisbury R, Thomas PP, Hazleman B. Prostaglandin E1 vasospastic disease and thermography. Ann Rheum Dis 1985;44:73-8.

48 Darton K, Black CM. Pyroelectric vidicon thermography and cold challenge quantify the severity of Raynaud's phenomenon. Br J Rheumatol 1991;30:190-5.

49 O'Reilly D, Taylor L, El-Hadidy K, Jayson MIV. Measurement of cold challenge responses in primary Raynaud's phenomenon and Raynaud's phenomenon associated with systemic sclerosis. Ann Rheum Dis 1992;51:1193-6.

50 Herrick A, El-Hadidy K, Marsh D, Jayson M. Abnormal thermoregulatory responses in patients with reflex sympathetic dystrophy syndrome. J Rheumatol $1994 ; 21: 1319-24$.
Wesseling H, den Heeten A, Wouda AA. Sublingual and oral isoxsuprine in patients with Raynaud's phenomenon. Eur J Clin Pharmacol 1981;20:329-33

52 Martin MFR, Dowd PM, Ring EFJ, Cooke ED, Dieppe PA, Kirby JDT. Prostaglandin E1 infusions for vascular insufficiency in progressive systemic sclerosis. Ann Rheum Dis $1981 ; 40: 350-4$

53 McHugh NJ, Csuka M, Watson H, Belcher G, Amadi A, Ring EFJ, et al. Infusion of iloprost, a prostacyclin analogue, for treatment of Raynaud's phenomenon in systemic sclerosis. Ann Rheum Dis 1988;47:43-7.

54 Shawket S, Dickerson C, Hazleman B, Brown MJ. Prolonged effect of CGRP in Raynaud's patients: a doubleProlonged effect of CGRP in Raynaud's patients: a doublePharmacol 1991;32:209-13.

55 Kyle MV, Belcher G, Hazleman BL. Placebo controlled study showing therapeutic benefit of iloprost in the treatment of Raynaud's phenomenon. J Rheumatol 1992; 19:1403-6.

56 Teh LS, Manning J, Moore T, Tully MP, O'Reilly D, Jayson MIV. Sustained-release glyceryl trinitrate patches as a treatment for primary and secondary Raynaud's phenomenon. Br J Rheumatol 1995;34:636-41.

57 Ring EFJ, Bacon PA. Quantitative thermographic assessment of inositol nicotinate therapy in Raynaud's phenomenon. J Int Med Res 1977;5:217-22.

58 Gush RJ, Taylor LJ, Jayson MIV. Acute effects of sublingual nifedipine in patients with Raynaud's phenomenon. J Cardiovasc Pharmacol 1987;9:628-31.

59 Neilson SL. Raynaud phenomena and finger systolic pressure during cooling. Scand J Clin Lab Invest 1978;38: 765-70.

60 Maricq HR, Weinrich MC, Valter I, Palesch YY, Maricq JG. Digital vascular responses to cooling in subjects with cold sensitivity, primary Raynaud's phenomenon, or sclero-
derma spectrum disorders. J Rheumatol 1996;23:2068-78.

61 Wigley FM, Malamet R, Wise RA. Reproducibility of cold provocation in patients with Raynaud's phenomenon. J Rheumatol 1987;14:751-5.

62 Corbin DOC, Wood DA, Housley E. An evaluation of finger systolic-pressure response to local cooling in the diagnosis of primary Raynaud's phenomenon. Clin Physiol 1985; 5:383-92.

63 Allen JA, Devlin MA, McGrann S, Dohery CC. An objective test for the diagnosis and grading of vasospasm in patients with Raynaud's syndrome. Clin Sci 1992;82:529-34.

64 Carter SA, Dean E, Kroeger EA. Apparent finger systolic pressures during cooling in patients with Raynaud's pressures during cooling in patients
syndrome. Circulation 1988;77:988-96.

65 Leppert J. Limitation of finger systolic pressure measurement as a diagnostic test for primary Raynaud's phenomneon in a female population. Clin Physiol 1989;9:457-65.

66 Kurozawa Y, Nasu Y. Toe systolic pressure after local cooling in primary Raynaud's phenomenon. Int Angiol 1994;13:215-17.

67 Hoare M, Miles C, Girvan R, Ramsden J, Needham T, Pardy B, et al. The effect of local cooling on digital systolic pressure in pation:

68 Maricq HR, Diat F, Weinrich MC, Maricq JG. Digital pressure responses to cooling in patients with suspected early vs definite scleroderma (systemic sclerosis) vs primary Raynaud's phenomenon. J Rheumatol 1994;21:1472-6.

69 Leppert J, Jonasson T, Nilsson H, Ringqvist I. The effect of isradipine, a new calcium-channel antagonist, in patients with primary Raynaud's phenomenon: a single-blind doseresponse study. Cardiovasc Drug

70 Weber A, Bounameaux H. Effects of low-dose nifedipine on a cold provocation test in patients with Raynaud's disease. J Cardiovasc Pharmacol 1990;15:853-5.

71 O'Reilly MJG, Talpos G, Roberts VC, White JM, Cotton LT. Controlled trial of plasma exchange in treatment of Raynaud's syndrome. BMJ 1979;1:1113-15.

72 Aylward M, Bater PA, Davies DE, Dewland PM, Lewis PA, Maddock J. Long-term monitoring of the effects of thymoxamine hydrochloride tablets in the management of patients with Raynaud's disease. Curr Med Res Opin 1982;8:158-70.

73 Klimiuk PS, Kay EA, Mitchell WS, Taylor L, Gush R, Gould $S$, et al. Ketanserin: an effective treatment regimen for digital ischaemia in systemic sclerosis. Scand J Rheumatol 1989;18:107-11.

74 Singh S, de Trafford JC, Baskerville PA, Roberts VC. Digital artery calibre measurement - a new technique of assessing

75 Naidu S, Baskerville PA, Goss DE, Roberts VC. Raynaud's phenomenon and cold stress testing: a new approach. Eur J Vasc Surg 1994;8:567-73.

76 Singh S, de Trafford JC, Baskerville PA, Martin JF. Response of digital arteries to endothelial dependant and independant vavsodilators in patients with Raynaud's phenomenon. Eur J Clin Invest 1995;25:182-5.

77 McIlroy MB, Targett RC, Roussin A, Seitz WS. Doppler ultrasonic investigation of Raynaud's phenomenon: effect of temperature on blood velocity. Ultrasound Med Biol 1985;11:719-25.

78 Greenstein D, Gupta NK, Martin P, Walker DR, Kester RC. Impaired thermoregulation in Raynaud's phenomenon. Angiology 1995;46:603-11. 
79 Greenstein D, Jeffcote N, Ilsley D, Kester RC. The menstrual cycle and Raynaud's phenomenon. Angiology $1996 ; 47: 427-36$

80 Brouwer RML, Wenting GJ, Schalekamp MADH. Acute effects and mechanism of action of ketanserin in patients with primary Raynaud's phenomenon. J Cardiovasc Pharmacol 1990;15:868-76.

81 Engelhart M, Neilsen HV, Kristensen JK. The blood supply to fingers during Raynaud's attack: a comparison of laser-Doppler flowmetry with other techniques. Clin Physiol 1985;5:447-53.

82 Pistorius MA, Planchon D, de Faucal P. Plethysmographic cold test for diagnosis and evaluation of the severity of Raynaud's phenomenon. Validation of the method by factorial analysis of correspondences in 541 patients. Int Angiol 1994;13:10-14.

83 Zamora MR, O'Brien RF, Rutherford RB, Weil JV. Serum endothelin-1 concentrations and cold provocation in
primary Raynaud's phenomenon. Lancet 1990;336: primary
84 Cooke ED, Bowcock SA, Smith AT. Photoplethysmography of the distal pulp in the assessment of the vasospastic hand. Angiology 1985:36:33-40.

85 Suichies HE, Aarnoudse JG, Wouda AA, Jentink HW, de Mul FFM, Greve J. Digital blood flow in cooled and contralateral finger in patients with Raynaud's phenomenon. Comparative measurements between photoelectrical plethysmography and laser Doppler flowmetry. Angiology 1992;43:134-41.

86 Kallenberg GGM, Wouda AA, Meems L, Wesseling H. Once daily felodipine in patients with primary Raynaud's phenomenon. Eur J Clin Pharmacol 1991;40:313-15.

87 Lafferty K, de Trafford JC, Potter C, Roberts VC, Cotton LT. Reflex vascular responses in the finger to contralateral thermal stimuli during the normal menstrual cycle: a hormonal basis to Raynaud's phenomenon. Clin Sci 1985;68: 639-45.

88 Cooke JP, Creager MA, Osmundson PJ, Shepherd JT. Sex differences in control of cutaneous blood flow. Circulation 1990;82:1607-15.

\title{
Unusual and memorable
}

\author{
Series editor: Gary D Wright
}

A 46 year old Indian woman presented with a 15 year history of painless, nodular swellings over the fingers and wrist of her right hand, which were making daily activities increasingly difficult. An excision biopsy three years before had revealed a calcifying aponeurotic fibroma, but the lesion had recurred. She was otherwise well with no other rheumatological or metabolic disease. Plain radiographs showed well defined, calcified lesions that appeared to erode the adjacent bone (fig 1).

Calcifying aponeurotic fibromata are rare soft tissue tumours, usually present in childhood and typically affect the fingers and palms. ${ }^{1}$

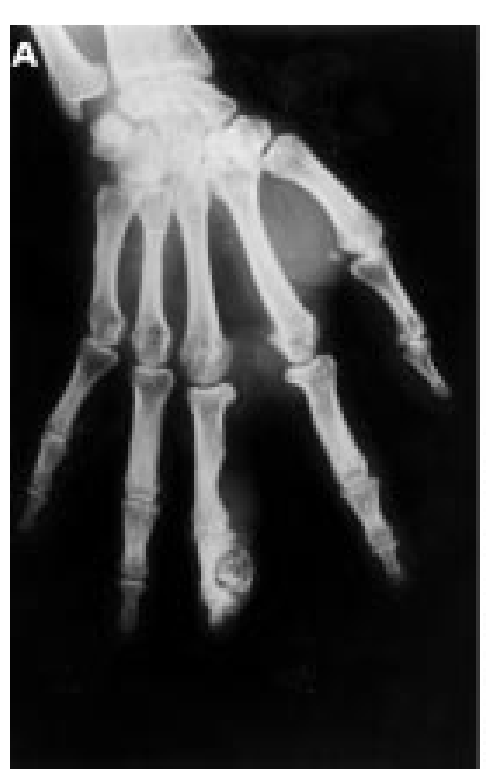

They are slow growing and painless, and almost never undergo malignant transformation. Histologically, they are characterised by lines of plump fibroblasts, surrounding areas of dense collagenous stroma with focal calcification. Treatment should be conservative, as local recurrence after excision is seen in $50 \%$ of cases.

1 Enzinger FM, Weiss SW. Soft tissue tumours. 3rd ed. Missouri: Mosby, 1995.

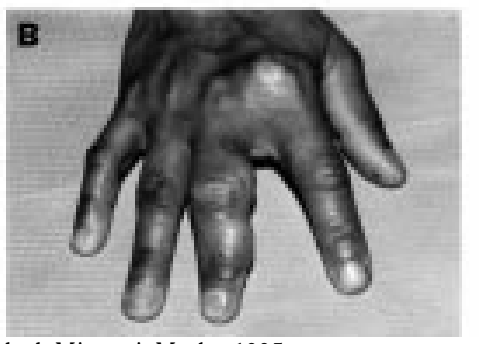

Contributors: IAN MCCURDIE, SLI S JAWAD. Rheumatology Department, The Royal Hospitals NHS Trust, Mile End Hosptial, Bancroft Road, London E1 4DG. 